\title{
A PERIODONTITE COMO POSSÍVEL FATOR DE RISCO PARA O NASCIMENTO DE CRIANÇAS PREMATURAS DE BAIXO PESO.
}

Miguel Angelo da CUNHA NETO; Luiz Felipe Gomes dos SANTOS; Joanna Gomes da CONCEIÇÃO; Carlos Marcelo da Silva FIGUEREDO.

O parto prematuro ocorre num período gestacional inferior a 37 semanas, uma vez que a gestação normal para humanos está em torno de 40 semanas. Crianças que ao nascimento possuem peso inferior a $2500 \mathrm{~g}$, são consideradas de baixo peso. A periodontite é uma alteração de origem multifatorial que acomete as estruturas que envolvem e suportam os dentes. $\mathrm{O}$ objetivo do trabalho foi realizar, por meio de uma revisão de literatura, uma análise sobre a importância da periodontite como fator de risco para o nascimento prematuro de crianças de baixo peso. A colonização da vagina por bactérias específicas tem sido associada com um aumento de $60 \%$ do riso de parto prematuro, e infecções no trato geniturinário têm sido associadas às complicações na gravidez durante muitos anos. Estudos recentes consideraram que mediadores inflamatórios presentes nas doenças periodontais tais como interleucina-1, fator de necrose tumoral $\alpha$ e prostaglandina $E_{2}$, possuem importante participação no início do trabalho de parto. Há evidências que ligam a infecção materna com o parto prematuro. O presente trabalho pode concluir que há indícios de que a periodontite faz parte do grupo de fatores de risco de grande valia para o mecanismo de indução ao parto prematuro de crianças de baixo peso. 